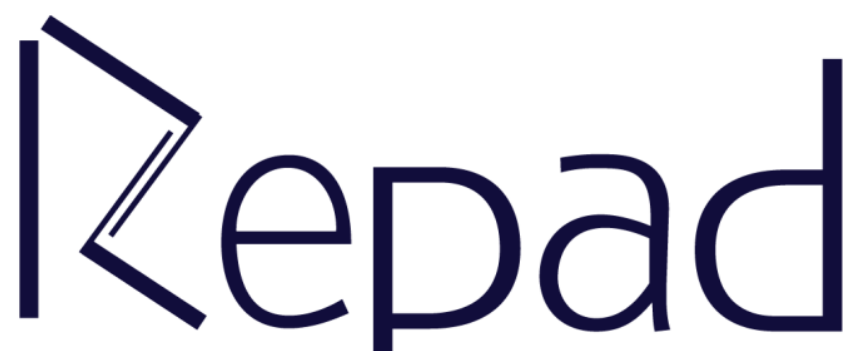

Vol. 3, n. 1, Abril/2019

Revista Estudos e

Pesquisas em Administração

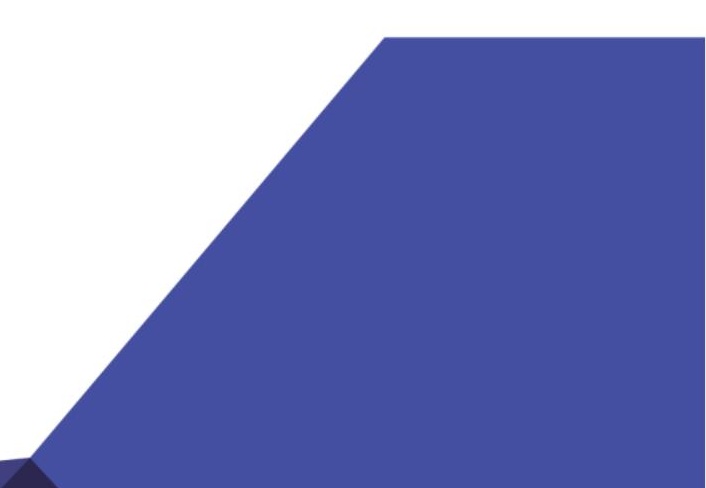




\title{
A APLICABILIDADE DOS 5 SENSOS COMO UMA FERRAMENTA ESTRATÉGICA DO LEAN MANUFACTURING - UM ESTUDO DE CASO NA INDÚSTRIA TEXTIL - CUIABÁ/MT
}

\author{
Rosicley Nicolao de Siqueira \\ FATEC SENAI MT \\ http://orcid.org/0000-0001-7944-1084 \\ Dhaiany Ellen Alves dos Santos \\ FATEC SENAI MT \\ http://orcid.org/0000-0001-5224-9148 \\ Cristiane Marafon \\ IST - Instituto de Tecnologia e Inovação \\ https://orcid.org/0000-0001-6154-3891 \\ Daiane Alves Cardoso \\ FATEC SENAI MT \\ http://orcid.org/0000-0002-1270-0448 \\ Andrey Sartori \\ FATEC SENAI MT \\ http://orcid.org/0000-0001-6882-3378
}

\section{RESUMO}

O Sistema Lean Manufacturing é um processo de melhoria continua composto de ferramentas estratégicas, onde através de sua implantação e execução, tem como resultado o baixo custo evitando o retrabalho, facilitando no desenvolvimento do processo, tornando-se uma gestão inovadora e agregando valores ao produto final. Diante disso, este artigo tem como objetivo apresentar a aplicabilidade dos 5 sensos em uma consultoria em Lean Manufacturing, realizado em dois setores: estoque de tecidos e processo de acabamento/expedição na linha de uniformes profissionais. Os objetivos específicos que direcionaram a construção do trabalho consistem em identificar os principais gargalos do processo, envolver as pessoas, aplicar a ferramenta nos setores problemáticos. Os resultados deste estudo apresentam a mudança do layout e adequações para melhoria da produtividade do setor de expedição e a organização do estoque. Essa implementação aconteceu de forma sistêmica, onde primeiramente identificaram-se as falhas no processo e onde era necessário um aprimoramento da execução das tarefas, em seguida fez-se a aplicação da ferramenta 5S. Com a aplicação da Ferramenta 5S nos setores envolvidos, implantaram-se as melhorias, possibilitando o levantamento quantitativo e qualitativo dos insumos e tecidos existentes proporcionado melhor otimização, reorganização e padronização das atividades.

Palavras-chave: Lean, Sensos, Processos

\section{THE APPLICABILITY OF THE 5 SENSES AS A LEAN MANUFACTURING STRATEGIC TOOL - A CASE STUDY IN THE TEXTILE INDUSTRY - CUIABÁ/MT}

\begin{abstract}
The Lean Manufacturing System is a process of continuous improvement composed of strategic tools, whose implementation and execution result in low cost, avoiding rework, facilitating in the development of the process, becoming an innovative management and adding value to the
\end{abstract}


final product. Therefore, this article aims to present the applicability of the 5 senses in a consulting company in Lean Manufacturing, carried out in two sectors: fabric stock and finishing / dispatch processes in the line of professional uniforms. The specific objectives that guided the study design are to identify the main bottlenecks of the process, to involve the people, to apply the tool in the problematic sectors. The results of this study present the layout change and adjustments to improve the productivity of the shipping sector and the organization of the stock. This implementation occurred in a systemic way, in which the process failures were first identified and the execution of the tasks needed to be improved, then the $5 \mathrm{~S}$ tool was applied. With the application of the $5 \mathrm{~S}$ Tool in the sectors involved, the improvements were implemented, enabling a quantitative and qualitative survey of the existing supplies and fabrics, providing better optimization, reorganization and standardization of activities.

Keywords: Lean, Senses, Processes

Datas Editoriais

Submetido: 08/04/2019

Aceito: $12 / 04 / 2019$

INTRODUÇÃO

Publicado: 28/04/2019

A filosofia 5S é uma estratégia diferencial para as organizações produtivas perante o cenário atual de competitividade, pois há constante busca por melhorias continuas como propostas de desempenho e qualidade, diminuição de custos, redução de desperdícios. Para Campos (1994) a ferramenta da qualidade 5S não proporciona apenas e unicamente em uma etapa de higienização e organização, a ferramenta oferece conceitos de atitude, disciplina e a socialização em um recinto empresarial, fatores importantes para uma melhoria. Diante disso, a implantação de uma filosofia $5 \mathrm{~S}$ torna-se indispensável, para a aplicabilidade de ferramentas de manufatura enxuta, ou demais ferramentas, metodologias e técnicas para melhoria de processos, qualidade e produtividade de uma empresa. Segundo Andrade (2008), o programa $5 \mathrm{~S}$, diferentemente de normas técnicas e padronizadas, tem o estudo baseado no ser humano e em sua essência viva, possuindo então um jeito particular de encarar desafios e aproveitar as oportunidades.

Observa-se que para se exercer uma estratégia de implantação das Ferramentas do Sistema Lean Manufacturing de qualidade requer sensibilização e conhecimento, não somente do sistema em si, mas do ambiente no qual será aplicado, tendo como visão a eficácia dos processos e/ou serviços. Segundo Silva (2003), todo programa de melhoria contínua deve começar com mudanças de costume dos trabalhadores no que se refere à organização, limpeza, asseio e ordem do ambiente de trabalho.

O estudo de caso direciona-se a uma empresa de médio porte e familiar. Diante disso, este artigo tem como objetivo apresentar a aplicabilidade dos 5 sensos em uma consultoria em Lean Manufacturing, realizado em dois setores: estoque de tecidos e processo de acabamento/expedição na linha de uniformes profissionais. Os objetivos específicos que direcionaram a construção do trabalho consistem em identificar os principais gargalos do processo, envolver as pessoas, aplicar a ferramenta nos setores problemáticos.

Este estudo subdividiu-se partindo-se da explicação da ferramenta $5 \mathrm{~S}$ visando a melhoria no sistema de produção da empresa em questão, em seguida apresentou-se a metodologia de como foi estruturado a realização do trabalho e discutiu-se os resultados demonstrando-se as mudanças realizadas. Para finalizar as apresentaram-se as conclusões pertinentes as atividades desenvolvidas. 


\section{REFERENCIAL TEÓRICO}

\section{O lean manufacturing e o processo produtivo}

A produção é a rede de processos e operações onde acontece à modificação da matériaprima que, por ser submetida a uma série de operações e procedimentos se transforma em um determinado produto final acabado. (SHINGO, 1996),

Verifica-se que o Sistema Toyota de Produção (STP), foi criado justamente para facilitar todo o processo de um setor de produção padrão, para assim obter um bom êxito em todo o desenvolvimento. Criado em período de crise do Petróleo, em 1973 pela Toyota Motor Corporation, sendo aplicado em muitas empresas Japonesas, que identificando a necessidade de uma mudança no seu sistema operacional adotaram a nova metodologia de trabalho.

O Sistema Toyota de Produção, não necessariamente, considera-se um novo sistema, mas, uma união do Sistema Taylor e Ford, ou seja, a gestão Científica, Taylorismo, em união com a linha de montagem em massa vindo do pensamento Fordista, exercida por um controle de processos, tendo como resultado um produto de qualidade, alcançando assim a eliminação de desperdícios e a fabricação com qualidade (WOMACK et al., 1992).

Resumidamente, esse sistema e todo o seu processo é visto pelo desenvolvimento de seu fluxo operacional, onde o desenrolar de materiais de produção em tempo e espaço, examinando o trabalho realizado separadamente de forma que cada setor complete o outro e somando todos é perceptível uma continuidade de todo sistema contínuo de produção.

O nome Lean Manufacturing foi citado originalmente na obra "A máquina que mudou o mundo", de Womack et al. (1992), em um resultado de um estudo que ressaltou a Indústria automobilística realizado pela MIT (Massachusetts Institute of Tecnology, EUA), embasado na Teoria do STP. Com isso podemos afirmar que o Lean é o aperfeiçoamento do Sistema Ford e do Sistema Taylor, pois não busca somente a melhoria da produção, mas, o baixo custo evitando o retrabalho, zerando o estoque e o mais importante, a facilidade no desenvolvimento de todo o processo (MOREIRA, 2000).

É constituído de seis ferramentas principais que proporcionam a melhoria no processo eliminando os desperdício no sistema produtivo garantindo a qualidade desejada, para o cliente/consumidor e ao produtor/empresário, sendo assim torna-se um empreendimento de gestão inovadora, pois tem como princípio manter os itens certos nos lugares, tempo e quantidade correta; criar e alimentar relações efetivas dentro da Cadeia de Valor; trabalhar de forma a cumprir-se uma Melhoria Continua em busca da Qualidade. (FLEURY; FLEURY, 2003; UBEDA; SANTOS, 2008).

Conforme Liker (2006, p. 286), as principais Ferramentas que compõem o Sistema Lean Manufacturing são:

- TRF Troca Rápida de Ferramenta

Redução e simplificação do setup, por meio da contenção e extinção das perdas relacionadas ao processo;

$-5 S$

Empenho de pessoas em organizar o local de trabalho por meio da preservação apenas do necessário, da limpeza, da padronização e da disciplina no cumprimento do trabalho, com o mínimo de supervisão possível;

- Fluxo Contínuo

Eliminar a paradas e os reinícios de produção que é típico de um sistema convencional, e ajuda na manutenção da qualidade detectando imediatamente a não conformidade.

(Lean Institute Brasil, 2009); 


\section{- Trabalho Padronizado}

Estabelece procedimentos precisos para o trabalho de cada um dos operadores em um processo de produção, baseado em três elementos: tempo takt, sequência e estoque padrão. (Lean Institute Brasil, 2003, p. 82);

- Produção Puxada

Os componentes produzidos em determinados estágios do processo devem chegar aos processos clientes nas quantidades e instantes corretos. (HUANG et al. 1998);

- Qualidade na Fonte:

Antecipar os defeitos potenciais buscando a sua causa raiz e eliminando-os previamente a fim de evitar que cheguem as mãos dos clientes internos ou externos.

\section{A FERRAMENTA 5S COMO UM DIFERENCIAL ESTRATÉGICO NOS RESULTADOS EMPRESARIAIS}

O $5 \mathrm{~S}$ surgiu em meados do século XX no Japão, e tem como base o empenho de organizar o ambiente de trabalho utilizando apenas aquilo que é necessário, a limpeza, padronização e disciplina, e consequentemente acabar com o desperdício e diminuir o número de acidentes e melhorar a produtividade, fazendo com que o seu desenvolvimento aconteça de forma prática e rotineira, sem a necessidade de uma cobrança ou supervisão. Para Pereira et al. (2012) e Tontini (1998), o programa ampara-se na manutenção das outras ferramentas da qualidade, colaborando para a organização de um ambiente produtivo e desenvolvendo a visão da empresa transformando a forma como os colaboradores veem o ambiente de trabalho tomando mais eficaz para se alcançar a qualidade total do processo.

A Ferramenta 5S é constituída por cinco palavras japonesas: Seiri, Seiton, Seiso, Seiktsou e Shitsuke. Onde, na língua portuguesa equivale a Arrumar, Ordenar, Limpar, Padronizar e Disciplina. Esta ferramenta é o alicerce para o fluxo produtivo, o controle visual e uniformização dos procedimentos. (HIRANO, 2004). Seguem as informações no Quadro 1.

Quadro 1. Definição da Ferramenta 5S

5s $\quad$ Senso De...

1. Seiri 1. Utilização

2. Seiton 2. Organização

3. Seisou 3. Limpeza

4. Seiketsu 4. Bem-estar

5. Shitsuke 5.autodiciplina
Como Fazer?

Definir o que é útil e o que não é. Fazer uma separação para possíveis descartes e reorganização do espaço para uma melhor produtividade.

Ordenar cada objeto em uma disposição mais inteligente, deixando o que é mais utilizado de forma mais fácil de ser acessado e com sinalização. Se usou, guarde de volta!

Entender a causa da sujeira e evitá-la sempre que possível. Utilize materiais para proteção, separe o que é reciclável. Se sujou, limpe!

Cuidar do bem-estar, higiene e segurança no ambiente. Promover ações que estimulem uma fácil comunicação para entendimento e resolução de desafios.

Disciplinar-se para tornar os $4 \mathrm{~S}$ anteriores em bons hábitos. Desenvolver autoconhecimento e criar ações que estimulem a melhoria contínua para o todo da organização.

Fonte: Hirano (2004) 
Alguns autores citam o 5S como a base para a Gestão da Qualidade Total, em que se para mudar a forma gerencial, antes de qualquer coisa, tem-se que arrumar e organizar o local de trabalho (VIEIRA, 2014).

No entanto, o programa 5S, não exige muita teoria, uma vez que a conscientização e o treinamento são feitos com os respectivos interessados e envolvidos no departamento de atuação, logo pode ser colocado em prática cada um de seus Sensos para resultado mais imediato.

Entretanto sabe-se que para que a execução desta ferramenta aconteça de forma eficaz, a gestão de pessoas (GP) tem um papel fundamental. Para Chiavenato (2008, p.14):

Não basta cuidar somente das pessoas. Ao cuidar dos talentos, GP precisa cuidar também do contexto onde elas trabalham. Isso envolve a organização do trabalho, a cultura corporativa e o estilo de gestão. Ao lidar com essas variáveis, a gestão de pessoas conduz à criação não somente de uma força de trabalho fortemente engajada como também a uma nova e diferente empresa.

Para se ter os resultados da implantação de qualquer mudança no processo produtivo, necessita-se, primeiramente que a gestão entenda a metodologia e envolva-se diretamente em todas as etapas. A partir disso, os colaboradores sensibilizados irão realizar as melhorais propostas resultando em um trabalho em equipe em busca de melhores resultados.

\title{
PROCEDIMENTOS METODOLOGICOS
}

No estudo de caso, iniciou-se com a implantação de um treinamento para os colaboradores para que as atividades ocorressem de forma eficaz. Em seguida realizou-se um levantamento de informações, mapeamento de fluxo de valor e abordagem dos colaboradores que trabalham nos setores onde seria implantada a ferramenta. De acordo Yin (2015, p. 04):

\begin{abstract}
"A pesquisa de estudo de caso surge do desejo de entender fenômenos sociais complexos. Em resumo um estudo de caso permite que os investigadores foquem um "caso" e retenham uma perspectiva holística e do mundo real como no estudo dos ciclos individuais da vida, o comportamento dos pequenos grupos, os processos organizacionais e administrativos, a mudança de vizinhança, o desempenho escolar, as relações internacionais e a maturação das indústrias".
\end{abstract}

Diante deste conceito, a aplicabilidade dos 5S na empresa analisada seguiu as etapas apresentadas a seguir:

Figura 1: Etapas das atividades realizadas

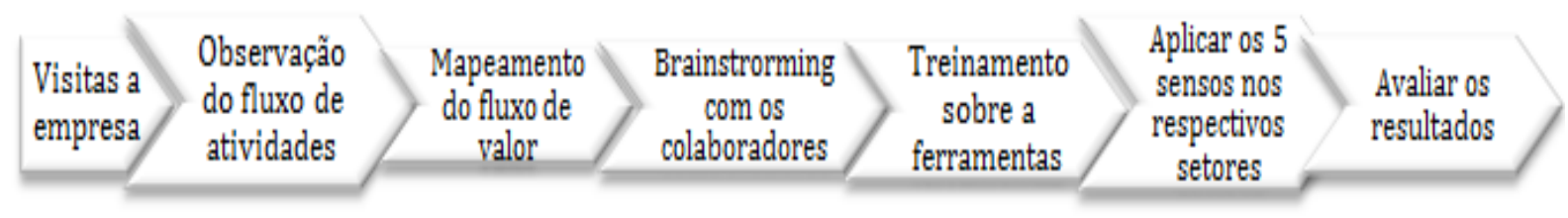

Fonte: Os autores (2018) 
A Ferramenta 5S foi aplicada no setor de expedição e no setor de estoque. No setor de expedição, foram sugeridas alterações no processo para favorecer o fluxo continuo evitando o acumulo de material em processamento. Já no setor do estoque foi realizado um planejamento para verificar como deveriam ser reorganizados os tecidos. Na discussão e resultados descrevese como foram realizadas as mudanças.

\section{DISCUSSÕES E RESULTADOS}

\section{Primeiro setor de atuação: expedição e a aplicabilidade dos 5 sensos}

No setor de expedição observaram-se algumas falhas na execução dos processos. Verificou-se que no setor de separação das peças pré-fabricadas são definidos quais pedidos serão encaminhados para a produção interna e quais serão encaminhados para facções. Ambos os pedidos são destinados para o setor de acabamento e depois passam pela expedição. Entretanto para adiantar alguns processos e "otimizar" os gastos com transportes, muitas vezes as peças eram encaminhadas para as facções sem serem bordadas, ao retornar essas peças ficavam acumuladas aguardando o bordado e não podiam ser expedidas. Sendo assim, estas permanecem paradas um determinado período dentro do processo aguardando uma destinação na produção gerando acumulo e congestionamento do fluxo.

No setor de expedição foi encontrado acúmulo de produtos, excesso de movimentação e transporte, resultando em um processo desorganizado sem definição adequada do layout e das atividades iniciais e finais. Para Monden (1984), a otimização do layout possibilita a eliminação das perdas existentes devido à movimentação e transporte de matérias e produtos, além de estimular o trabalho em equipe e facilitar o feedback de qualidade, possibilitando melhores resultados de qualidade e produtividade. Diante disso foi necessária a reestruturação do layout do setor de expedição, facilitando assim a movimentação dos colaboradores e reorganização das atividades.

Figura 2: Reorganização do Layout antes e depois do $5 \mathrm{~S}$ no setor de expedição.

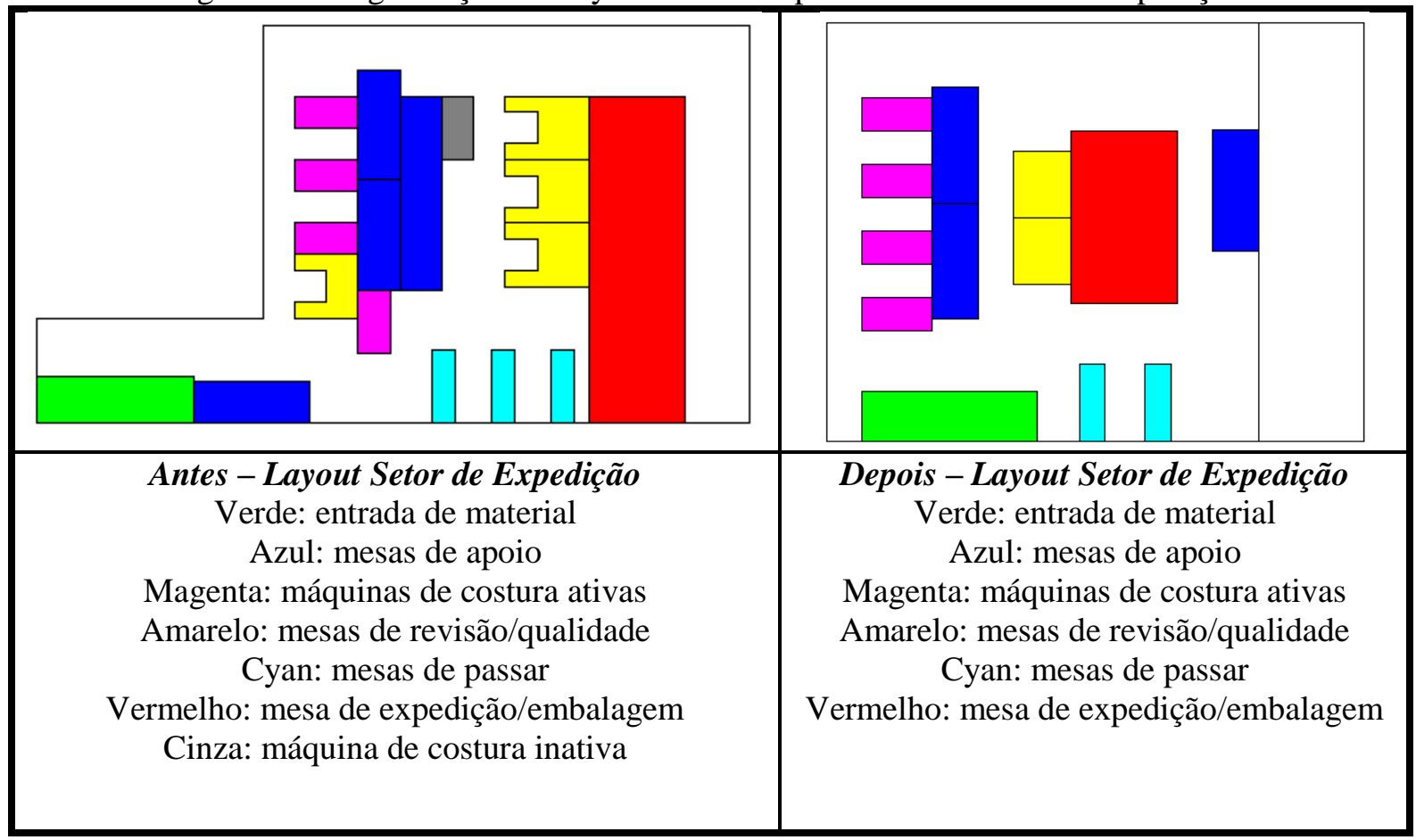

Fonte: A pesquisa (2018) 
Na Figura 3, podemos como estava organizado o layout, demonstrando claramente materiais desnecessários, excesso de mesas e bordas, pouco espaço para movimentação no processo e um grande acumulo de peças sendo produzidas em grandes lotes o que ocasiona morosidade no processo.

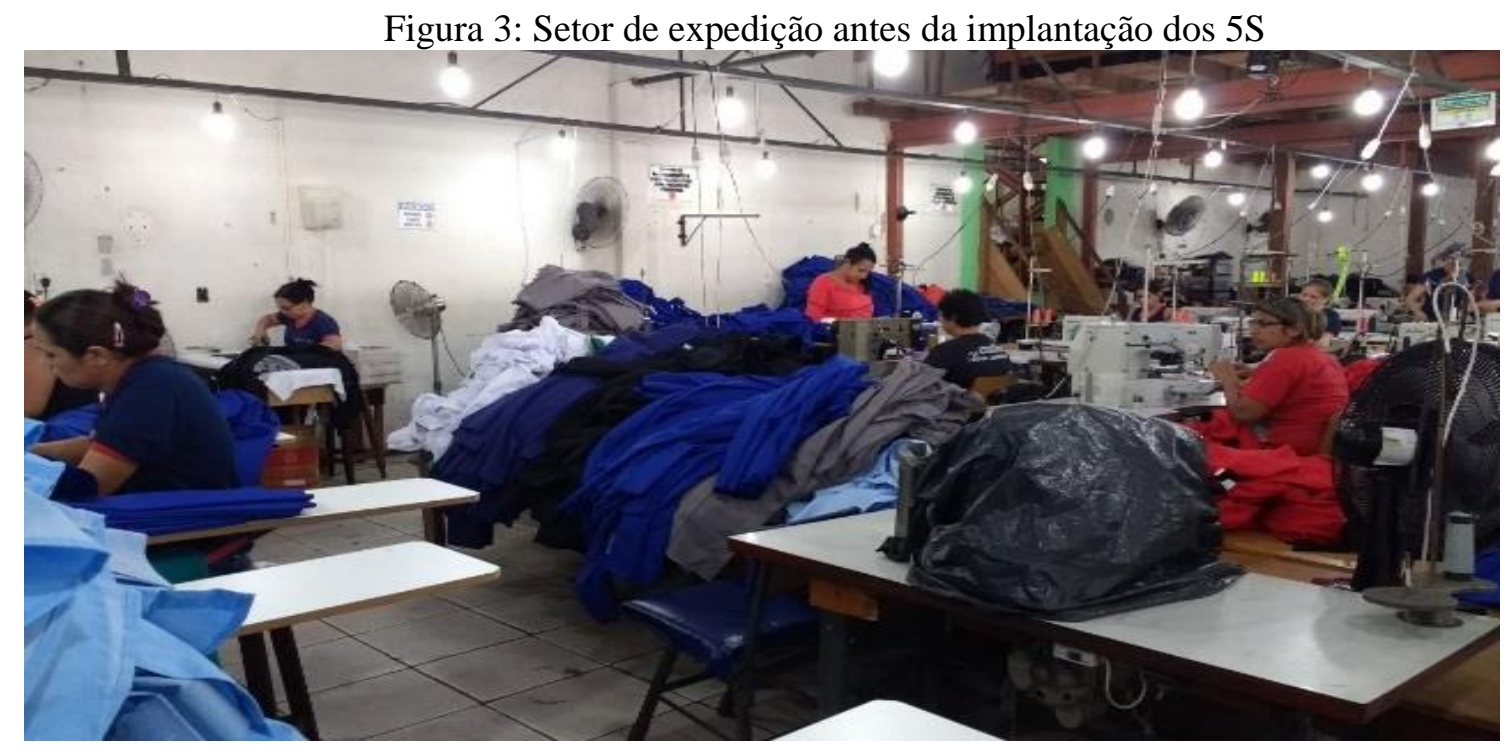

Fonte: A pesquisa (2018)

Após a implantação do 5S, conforme a figura 4, é possível visualizar uma organização de todo o setor, com a aplicabilidade do fluxo continuo a partir da diminuição dos lotes, e da redistribuição das atividades. Essas mudanças resultaram-se na redução do acúmulo de peças em processamento e o excesso do tempo de movimentação dos colaboradores, além da definição de uma única entrada e uma única saída para as peças, ganhando assim tempo para a execução das tarefas que envolvem o setor.

O processo final de embalagem e expedição era realizado por uma única operadora que trabalhava por lotes. Dessa forma, todas as peças do pedido passavam pela primeira etapa para seguirem para a segunda etapa e assim por diante. A sequência de processamento era a seguinte:

- Dobrar a peça;

- Escrever a informação referente ao tamanho na própria peça (se P, M, G, 42, 44, 46, etc);

- Ensacar as peças;

- Fechar as embalagens com fita durex;

- Escrever a numeração/tamanho na embalagem;

- Encaixotar;

Foram sugeridas alterações nos processos para favorecer o fluxo contínuo. Dessa forma, foram providenciadas etiquetas adesivas de forma que a mesma seja usada para fechar a embalagem e para informar o tamanho da peça embalada. Além disso, utilizou-se o princípio do one piece flow para a embalagem das peças, de forma que a operadora processe uma peça por vez, evitando o acúmulo de material em processamento.

Após as modificações, a sequência de processamento ficou:

- Dobrar a peça;

- Ensacar as peças;

- Fechar as embalagens com a etiqueta;

- Encaixotar; 
Ainda, baseando-se no princípio do fluxo contínuo, foram realizados ajustes no layout do setor de forma a favorecer o fluxo dos produtos reduzindo assim o acúmulo de peças em processamento e o excesso de movimentação e transporte. Para Shingo (1996), todos os sistemas de produção podem ser analisados sob duas perspectivas: função processo e função operação, onde: (i) função processo: o fluxo do produto (matérias, tarefas, ideias) no tempo e no espaço, rompendo assim com o paradigma tradicional de just in case, que enxergava o processo com um conjunto de operações; função operação: o fluxo do sujeito de trabalho no tempo e no espaço, ou seja, os operadores e as maquinas. A figura abaixo demonstra como ficou o setor de expedição após a implantação da ferramenta.

Figura 4: Expedição depois da aplicação da Ferramenta 5S.

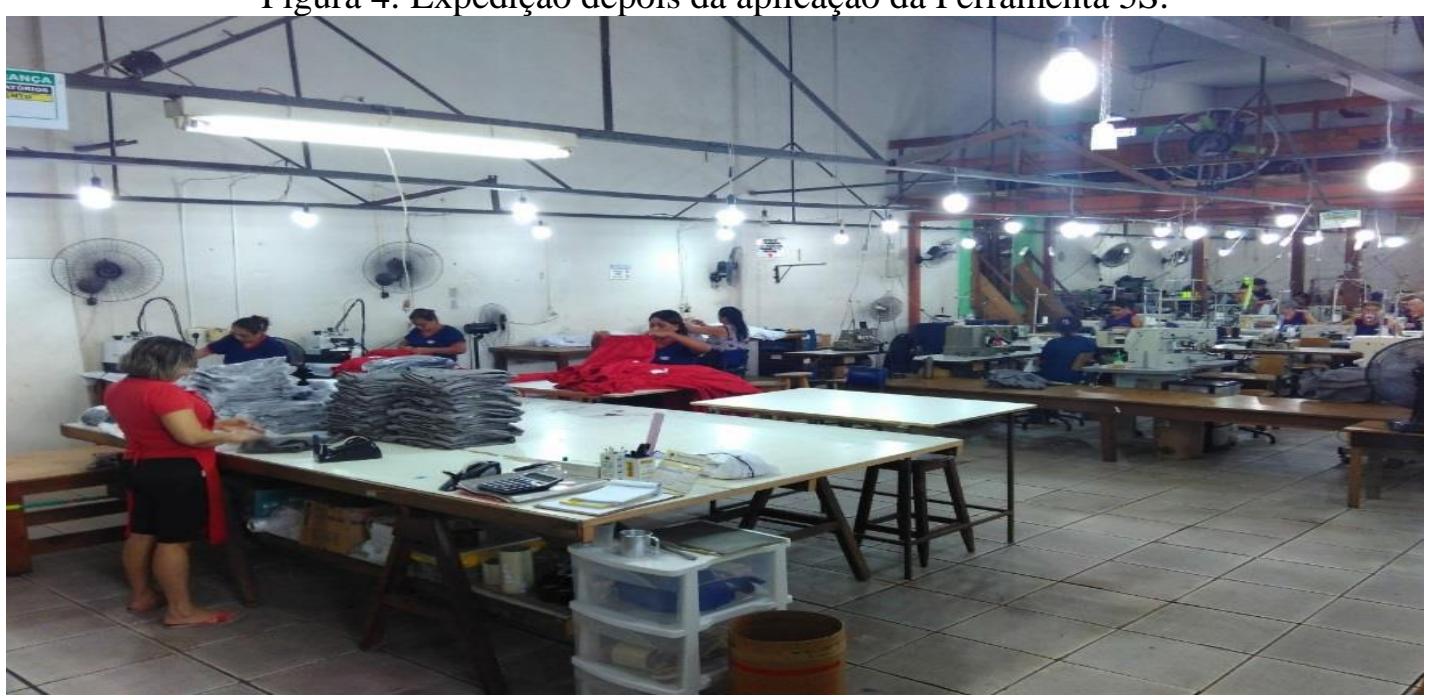

Fonte: A Pesquisa (2018)

\section{Segundo setor de atuação: estoque de tecidos}

Além do setor de expedição a ferramenta também foi aplicada no setor de estoque, onde pode ser identificada uma falta de padronização no armazenamento das matérias primas (tecidos), ocasionando perdas e retrabalho na execução dos processos gerando excesso de movimentação trazendo para o setor em questão uma situação de desordem visual e quantitativa. Para Borges et al. (2010), um bom gerenciamento de estoques ajuda na redução dos valores monetários envolvidos, de forma a mantê-los os mais baixos possíveis, mas dentro dos níveis de segurança e dos volumes para o atendimento da demanda.

No setor de estoques de tecidos, foi identificada a falta de padronização resultando assim no retrabalho e possíveis perdas de tecidos, ocasionando possíveis entraves no e atrasos nos demais setores que dependem deste para continuidade no fluxo de atividades. Na Figura 5, observa-se a retirada de todos os tecidos para organização e quantificação. Para melhor exemplificar as atividades, as etapas iniciaram-se a partir do planejamento das baias onde seriam armazenados os tecidos. 
Figura 5: Estoque antes da aplicação da Ferramenta 5S

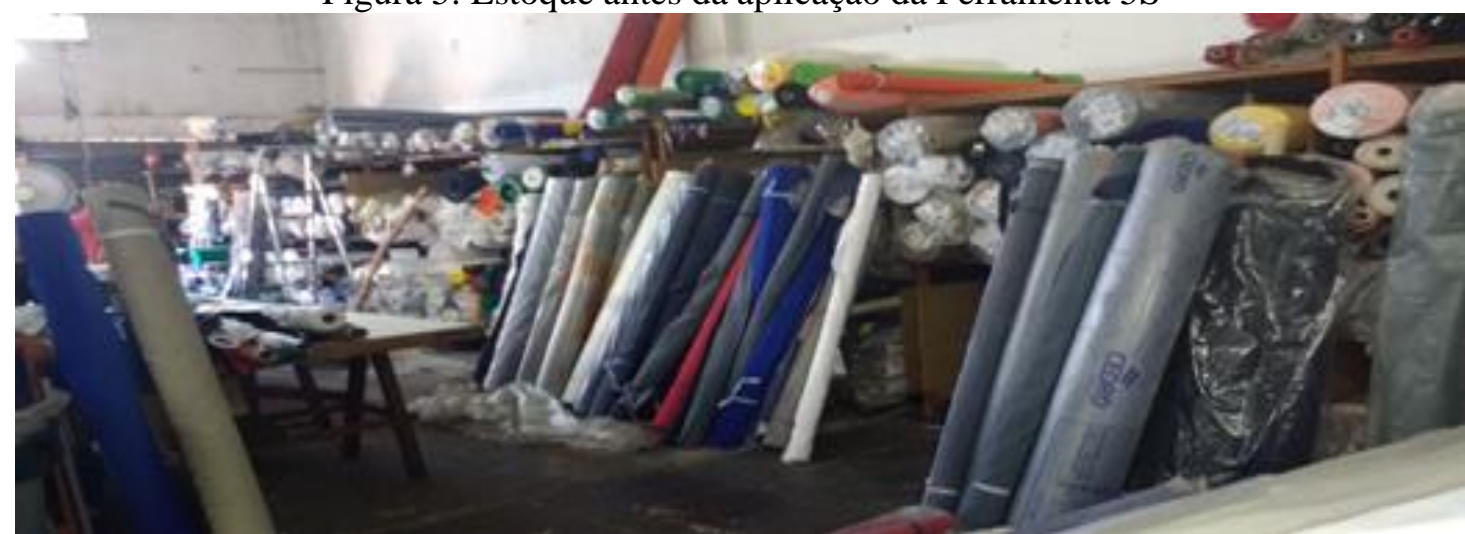

Fonte: A pesquisa (2018)

Foi realizado um planejamento identificando qual a melhor forma para reorganizar os tecidos e aos poucos foi implantando cada S no setor. Primeiro aplicou o senso de utilização, observando-se o que realmente era importante e necessário para o setor em questão, separando o que era utilizável e descartando o que não prestava mais para produção, para isso foi necessário retirar todo da armazenagem. Conforme a Figura 6, observa-se a situação atual do senso de utilização e organização.

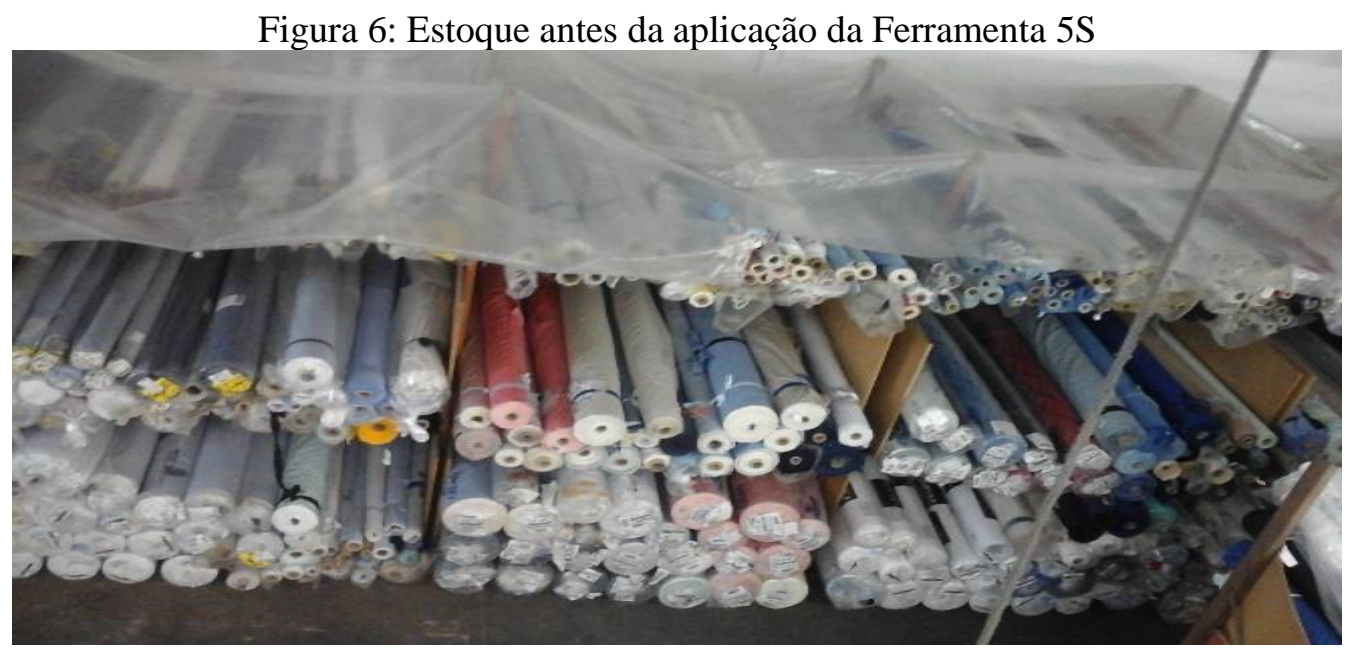

Fonte: A pesquisa (2018)

Além disso, de acordo com a Figura 7, reorganizaram-se os tecidos por tipo e cores, fezse a pesagem dos tecidos para um controle quantitativo e posteriormente lançamento das informações em um sistema de controle de estoque. Realizou-se também o senso de organização por cores para que as baias fossem preenchidas com tecidos por finalidade e necessidade. $\mathrm{O}$ 'senso de ordenação' pode ser definido como "um otimizador da área de trabalho", pois consiste em definir critérios e locais apropriados para estocagem, depósitos de ferramentas e materiais, armazenamento e fluxo de informações, ou seja, "fazer com que as coisas necessárias sejam utilizadas com rapidez e segurança, a qualquer momento" (HABU et al, 1992). Para finalizar realizou-se a identificação visual da separação dos tecidos. 
Figura 7: Estoque finalizado depois da aplicação da ferramenta

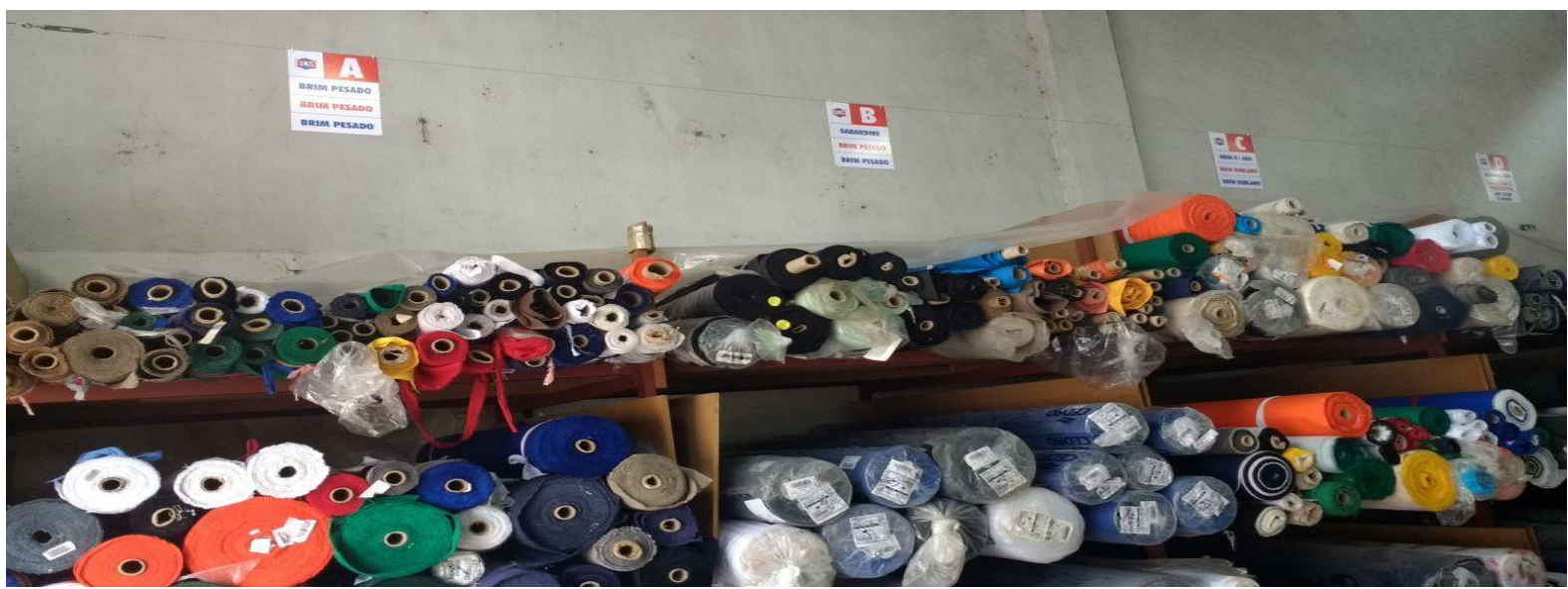

Fonte: A pesquisa (2018)

Depois que a ferramenta foi aplicada no setor de estoque é visível à organização e padronização como nos apresenta as figuras acima relacionadas. Resultado assim em uma melhoria visual e setorial possibilitou-se uma visualização da matéria prima disponível para utilização e, além disso, agilidade para localização dos tecidos a serem direcionados para o setor de corte.

\section{CONSIDERAÇÕES FINAIS}

Com a filosofia da Ferramenta 5S nos setores envolvidos, observou-se as necessidades de melhoria na Empresa, onde possibilitou o levantamento quantitativo e qualitativo dos insumos, tecidos, existentes e um melhor aproveitamento do espaço, reorganização e padronização dos mesmos. A perda de lucratividade está intimamente relacionada ao desperdício, uma vez que está embutida nos custos gerados por esses.

Esses desperdícios foram detectados, tanto no processo produtivo, quanto em outras áreas. No layout, o mobiliário disposto de maneira inadequada para o trabalho, acarretando desperdício de tempo e movimentação de pessoas e materiais, o que é refletido no tempo de produção. Conclui-se que, para a empresa tornar-se mais competitiva, necessita modificar seus paradigmas culturais. A implantação do Programa 5S denota o movimento das organizações, da posição atual, para uma posição futura, desejável e competitiva no mercado.

Entretanto, sabendo-se que um setor está inteiramente ligado ao outro e um processo reflete na execução do processo posterior, acredita-se que para melhor produtividade no processo de fabricação da empresa analisada de forma geral, os resultados serão ainda mais significativos, se for aplicado este ou outro sistema de padronização, em todos os setores da indústria em questão.

Com isso conclui-se que, de fato, quando se identifica onde é necessário ajustar é possível colher uma melhoria, ressaltando que para o sucesso de qualquer mudança a gestão de pessoas é a primeira estratégia para o início das atividades. 


\section{REFERÊNCIAS}

ANDRADE, W. M. Equipe 5S - Praticando o PDCA. Belo Horizonte: Soluções Criativas, 2008.

BORGES C. T.; CAMPOS S. M.; BORGES C. E. Implantação de um sistema para o controle de estoques em uma gráfica/editora de uma universidade. Revista Eletrônica Produção \& Engenharia, v. 3, n. 1, p. 236-247, Jul./Dez. 2010.

CAMPOS, V. F. TQC: Gerenciamento da rotina do trabalho do dia-a-dia. 3. ed. Rio de Janeiro: Bloch, 1994

COSTA, R.M.C. et al. Como praticar o 5S na escola. 2 ed. Belo Horizonte: Líttera Maciel, 1996.

CAULLIRAUX, H.; CAMEIRA, R. A consolidação da visão por processos na engenharia de produção e possíveis desdobramentos. XX ENEGEP, São Paulo, 2000.

CAMPOS, R. et al. A ferramenta 5S e suas implicações na gestão da qualidade total. SimpepSimpósio de Engenharia de Produção, v. 12, 2005.

CARDOSO, R. Análise da aplicabilidade dos princípios e ferramentas da produção enxuta para melhoria da gestão de processos operacionais de educação a distância em instituições de ensino superior. 2010. Tese de Doutorado. Universidade Metodista de Piracicaba.

CHIAVENATO, I. Gestão de pessoas. Elsevier Brasil, 2008.

DE JESUS PACHECOA, D. A. Teoria das Restrições, Lean Manufacturing e Seis Sigma: limites e possibilidades de integração. Production, v. 24, n. 4, p. 940-956, 2014.

FERREIRA, N. F. F. Desenvolvimento de um jogo de simulação do sistema de produção LEAN ferramentas: 5S, organização de layout e TPM. 2012. Tese de Doutorado. Instituto Politécnico do Porto. Instituto Superior de Engenharia do Porto.

FOGLIATTO, F. S.; FAGUNDES, P. R. M. Troca rápida de ferramentas: proposta metodológica e estudo de caso. Gestão e produção. São Carlos, SP. vol. 10, n. 2 (2003), p. 163-181, 2003.

HABU, N.; KOIZUMI Y.; OHMORI Y. Implementação do 5S na prática. Campinas: Editora Icea, 1992.

LIKER, J. K. Modelo Toyota: os 14 Princípios de gestão do maior fabricante do mundo. Porto Alegre: 2006.

LIKER, J. K.; MEIER, D. O Modelo Toyota-Manual de Aplicação: Um Guia Prático para a Implementação dos 4Ps da Toyota. Bookman Editora, 2007

LINDGREN, P. C. C. Implementação Do Sistema De Manufatura Enxuta (Lean 
Manufacturing) Na Embraer. Monografia (MBA em Gerência de Produção e Tecnologia)Departamento de Economia, Contabilidade, Administração e Secretário Executivo, Universidade de Taubaté, Taubaté, 2001

LUZZI, A. A. A. Uma abordagem para projetos de layout industrial em sistemas de produção enxuta: um estudo de caso. 2004.

MARIZ, R. N. Método para aplicação do trabalho padronizado. Ambiente Construído, 2013.

SCHNEIDER J., WALDYR E. Análise da trajetória tecnológica e da dinâmica da implantação do pensamento enxuto em uma empresa do setor plástico: um estudo de caso. 2007.

PEREIRA, L; GODOY, D; TERÇARIOL, D. Estudo de caso como procedimento de pesquisa científica. Psicologia. Reflexão. Crit. vol.22 no.3 Porto Alegre 2009.

PEREIRA, K. L. B.; CAMARGO, R. C.; SANTOS, V. P.; LOPES, V. T. Programa 5s: Uma ferramenta para eliminar desperdícios e otimizar os custos no processo produtivo. [Editorial]. Revista Cientifica do Unisalesiano - Lins - SP, ano 3., n.7, jul/dez de 2012.

YIN, R. K. Estudo de Caso: Planejamento e Métodos. Bookman editora, 2015. 